\title{
Dental Care Management in a Child with Recessive Dystrophic Epidermolysis Bullosa
}

\author{
Carolina Paes TORRES \\ Jaciara Miranda GOMES-SILVA \\ Thalita Siqueira MELLARA \\ Lívia Pasqualini CARVALHO \\ Maria Cristina BORSATTO \\ Department of Pediatric Clinic, Preventive and Community Dentistry, Ribeirão Preto Dental School, \\ USP - University of São Paulo, Ribeirão Preto, SP, Brazil
}

\begin{abstract}
Epidermolysis bullosa (EB) is a heterogeneous group of rare genetic disorders characterized by marked fragility of the skin and mucous membranes in which vesiculobullous lesions occur in response to trauma, heat or no apparent cause. The recessive form of EB presents the greatest oral alterations including repeated blistering and scar formation leading to limited oral opening, ankyloglossia, tongue denudation, microstomia, vestibule obliteration and predisposition to oral carcinoma. Routine dental care may cause bullae formation on the lips and oral mucosa. Together with the ingestion of soft and frequently carbohydrate food, these anomalies lead to a high caries risk. This paper documents a case of a child diagnosed with recessive dystrophic epidermolysis bullosa (RDEB); describes the phases and difficulties of dental treatment and the measures that dentists and health care providers should adopt in order to provide a safe and effective dental treatment as well as earlier prevention to these patients.
\end{abstract}

Key Words: Epidermolysis bullosa, dental care, special needs patient.

\section{INTRODUCTION}

Epidermolysis bullosa (EB) refers to a group of hereditary diseases which are characterized by blistering of tissues containing stratified epithelia $(1,2)$. Traditionally, EB has been divided into four broad categories based on the level of blistering within the dermal-epidermal junction, namely, EB simplex (EBX), junctional EB (JEB) and dystrophic EB (DEB), which comprises dominant and recessive variants, and Kindler syndrome, which is a mixed level of cleavage (1). The reported incidence varies between 1:50,000 to 1:500,000 live births. EB affects all racial and ethnic groups, there is no gender predominance and often manifests at birth or during the first year of life (3-5).

Dystrophic EB is inherited in both dominant and recessive forms, caused by mutations in the type VII collagen gene, and is characterized by sub-lamina dura separation, due to blistering below the lamina densa of the basement membrane zone $(3,4)$. There is excessive collagenolysis resulting in reduced or absent collagen VII, a fibrous protein that is the main component of the anchoring filaments (5-10). The worst form of EB is the recessive subtype (RDEB), because in patients with this condition the skin is fragile and a minimal mechanical trauma induces the formation of blistering and profound skin ulceration (11). The continuous formation of cicatricial tissue, especially in the hands and feet, leads to the joining of the fingers and toes (5). The oral, pharyngeal and esophageal mucosas are intensively compromised by scarring and tissue shrinkage $(7,11)$. Squamous cell carcinoma is the most frequent complication of $\mathrm{EB}(12,13)$.

Individuals with the RDEB typically have extreme fragility of their oral and perioral mucosa, and ulcerations can affect all areas of the oral mucosa, including the tongue. The lesions heal with scarring. The continuous process of blister formation and healing with scarring results in marked changes in the oral architecture. The tongue loses the lingual papillae

Correspondence: Profa. Dra. Maria Cristina Borsatto, Departamento de Clínica Infantil, Odontologia Preventiva e Social, Faculdade de Odontologia de Ribeirão Preto, Universidade de São Paulo, Avenida do Café S/N, 14040-904 Ribeirão Preto, SP, Brasil. Tel: +55-16-3602-4114. Fax: +55-163633-0999. e-mail: borsatto@forp.usp.br 
and becomes bound down to the floor of the mouth, which is a condition known as ankyloglossia. Anatomic structures, such as the palatal rugae, are ablated. The oral vestibules become obliterated with the soft tissue attachment advancing. The soft tissues defining the oral opening fail to grown normally due to scarring, resulting in a typically markedly restricted oral aperture. The presence of severe microstomia can impede the degree to which affected individuals can open their mouth (10). Individuals with severe generalized recessive dystrophic EB are at increased risk of squamous cell carcinoma development. Although carcinomas occur with far greater frequency on the skin in individuals with EB, they can occur intraorally (13-15).

This paper documents a case of a child diagnosed with RDEB, describing the phases and difficulties of dental treatment and the measures that dentists and health care professionals should adopt in order to provide a safe and effective dental treatment as well as earlier prevention to these patients.

\section{CASE REPORT}

An 11-year-old Caucasian patient came to the Center for Formation of Human Resources Specialized in Dental Care for Special Needs Patients at the Ribeirão Preto Dental School, University of São Paulo, Brazil, for general dental care. The child was referred to our service by the Department of Genetics of the University Hospital of Ribeirão Preto (University of São Paulo, Brazil) where she was undergoing medical treatment since birth, at which time she had been diagnosed as having RDEB. According to the medical records, patient was hospitalized at the ages of 6 with chronic anemia due to malnutrition, 7 due to hepatitis $\mathrm{B}$, and 8 for surgical treatment of the hands.

Physical examination revealed dystrophic hands and feet with joined fingers, regional ulcerations throughout the body, and even mild alopecia was observed (Fig. 1). Extraoral examination showed fibrous scars bands bilaterally at the commisures of the lips, resulting in a limited mouth opening (Fig. 2 A,B). Intraoral examination revealed bullae as well as severe scarring of the mouth and hemorrhagic lesions extending throughout the mucosa. The patient also had a denuded tongue and microstomia, which limited her ability to open the mouth. Poor oral hygiene leaves to ulcerative gingivitis and carious lesions on occlusal surfaces of the first permanent molars and upper primary canines. Oral hygiene measures were not practiced due to the eruption of oral bullae following toothbrushing trauma and the difficulty in holding the toothbrush since her hands and fingers had become claw-like through repeated scarring. A comprehensive radiographic examination (periapical and panoramic radiographs) was accomplished to outline a logical and realistic dental treatment planning. The radiographic investigation confirmed the presence of decayed teeth and agenesis of the mandibular right lateral incisor. No bone pathology was observed (Fig. 2 C,D,F).

The clinical and radiographic findings along with the information gathered from the medical/dental history provided undisputable evidence that the child was at high caries risk and activity. Therefore, the treatment strategies included the adoption of preventive measures for adequacy of the oral conditions, which comprised elementary instruction on oral health care, diet counseling and improvement of oral care skills by means of supervised toothbrushing and training of the parents on toothbrushing and flossing since the development of scarring and hand contractures further complicates oral hygiene. The gentle use of a soft baby-size toothbrush was encouraged as an effort to minimize the mucosa's trauma. Afterwards, it was observed a decrease in the formation of bullae following toothbrush trauma.

The patient's high-risk condition as well as the treatment strategies to be adopted, was thoroughly explained to the parents and both were required to be willing and compliant with treatment. Furthermore, much time and effort were invested in highlighting that oral homecare should be supportive to the professional care provided at the clinics and that family commitment was primordial for achieving and maintaining an adequate oral health status. It was strongly emphasized that positive and lasting outcomes could not be reached unless they completely understood the relevance of a partnership approach.

The treatment strategies included the use of a disclosing agent to reveal dental plaque, professional prophylaxis, topical applications of $0.12 \%$ chlorhexidine gluconate and $1.23 \%$ acidulated phosphate-fluoride gel. The goals of this phase of the therapy were mainly to provide the patient with an effective psychological conditioning, motivate and stimulate her commitment with the treatment.

The restorative/rehabilitative procedures were carried out under local anesthesia, at sequentially scheduled appointments in ambulatory environment. The maxillary and mandibular premolars were sealed 
with a resin-based sealant (Fluroshield ${ }^{\circledR}$, Dentsply/ Caulk, Milford, DE, USA). The decayed maxillary and mandibular first molars and upper primary canines were restored. Extreme care is necessary to avoid trauma and ulcerations during an oral examination and dental treatment. Therefore, protection with lubricant (petroleum jelly) was done on all perioral tissues and commisures, as well in the intraoral mucosa before each treatment procedure. Instructions on toothbrushing and dietary habits were emphasized at each treatment
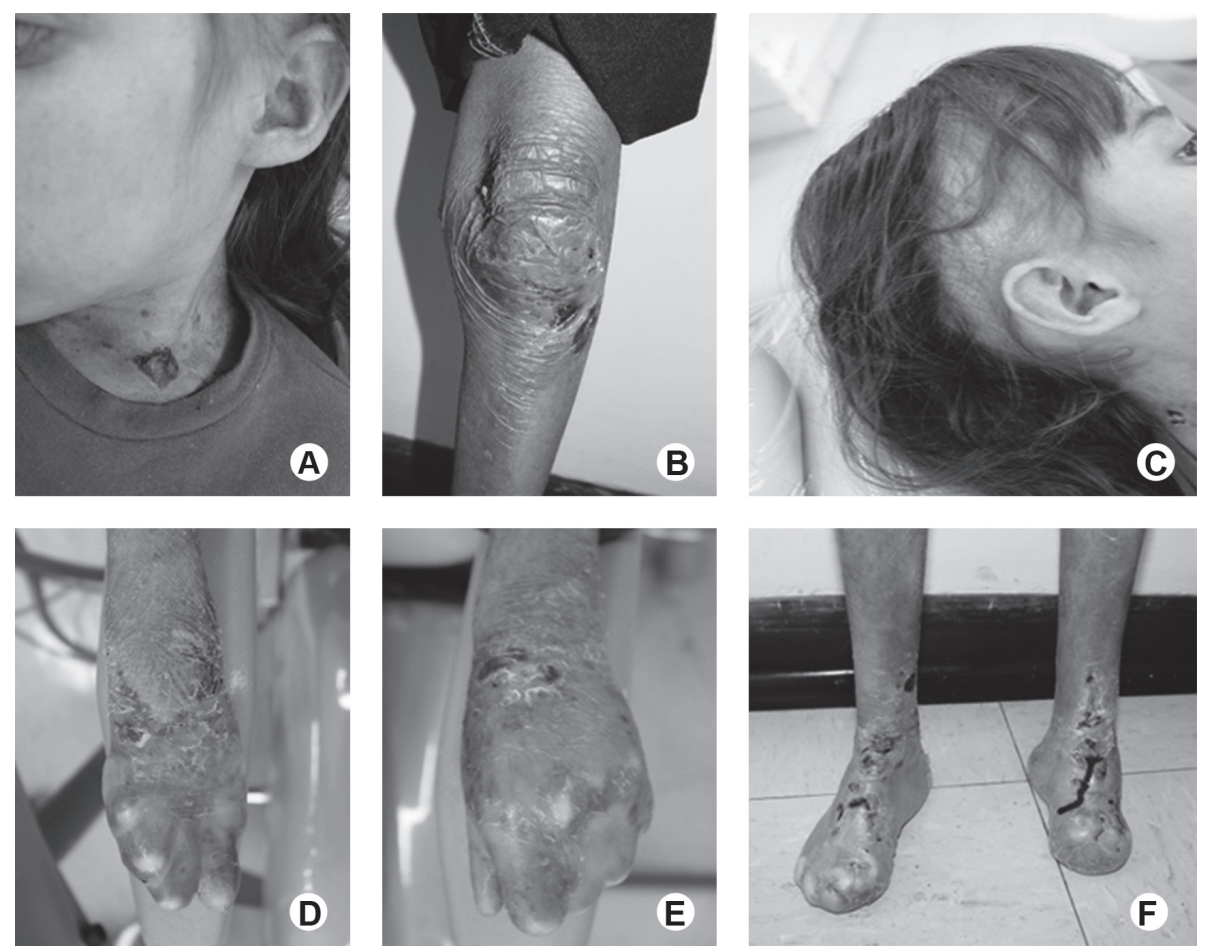

Figure 1. Physical aspects. A-B= Regional ulcerations throughout the body; $\mathrm{C}=$ Alopecia; $\mathrm{D}, \mathrm{E}=\mathrm{D}$ ystrophic hands with joined fingers; $\mathrm{F}=$ Dystrophic feet.
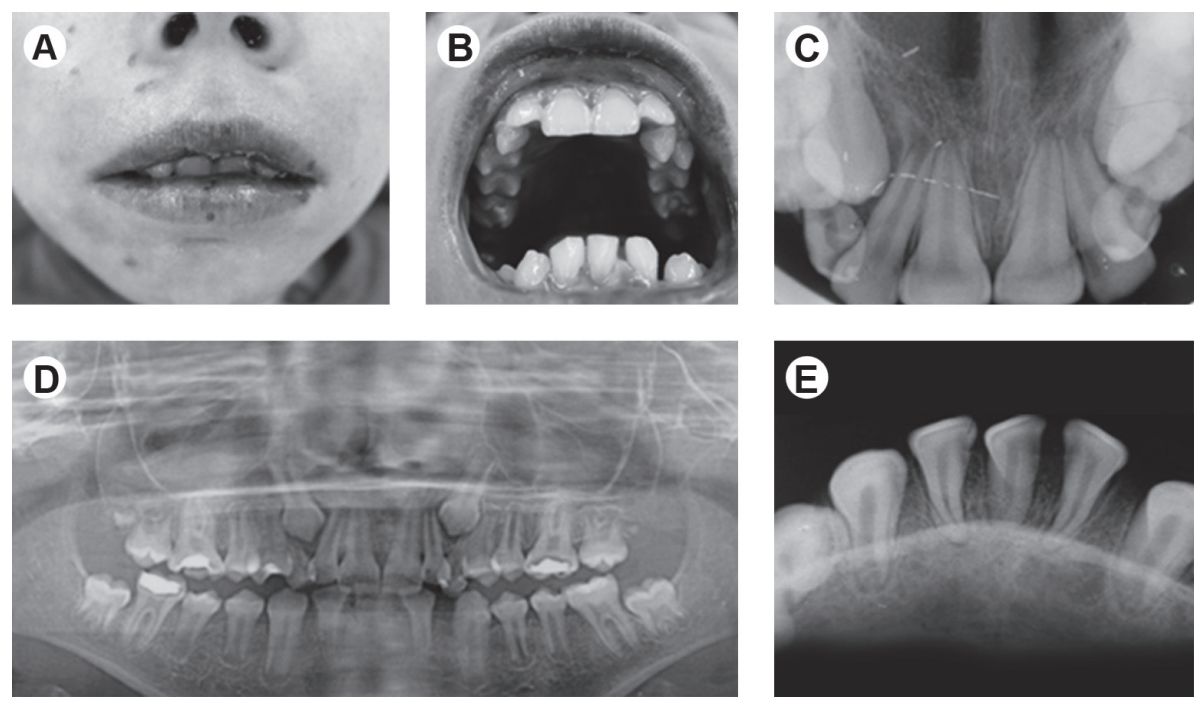

Figure 2. Oral aspects. A= Fibrous scars bands bilaterally at the commisures of the lips; $B=$ Limited mouth opening; $C, D, E=$ Radiographic investigation. Note the agenesis of the mandibular right lateral incisor and the absence of bone alteration. 
appointment.

The returned for monthly follow-up recalls for monitoring dental plaque control, possible onset of new lesions and periodontal conditions. In addition, due to the patient's clear difficulty on toothbrushing, professional prophylaxis and topical applications of chlorhexidine gluconate and fluoride were done at each visit. Afterwards, a decrease in the dental plaque was observed.

\section{DISCUSSION}

The recessive form of dystrophic EB is the more severe in which a minimal mechanical trauma induces the formation of blistering and profound skin ulceration (11). The most significant complication in adults with EB is the cutaneous squamous cell carcinoma (SCC). By mid-adulthood, nearly all will have had at least one SCC, and nearly $80 \%$ will have died of metastatic SCC despite aggressive surgical resection (14). Therefore, these individuals should be extravigilant in monitoring changes in oral ulcerations, such as the development of raised, indurated borders.

The hands and the feet have a tendency to suffer repeated cycles of blistering, ulceration, resulting in dystrophic scars. The sequelae of chronic scarring include progressive digital fusion (syndactyly) as well as the severe contraction of the fingers and thumb. The mucous membranes of the mouth and the entire gastrointestinal tract are intensively compromised by scarring and tissue contraction, making difficult to eat and defecate $(5,8,11)$. The patient of this case presented extensive skin lesions in the form of bullae with some scaring on her trunk, extremities, neck and face, limited mouth opening, contractures and syndactyly on her fingers and toes.

The RDEB presents as greatest oral manifestations vesicles that rapidly tear, even with a diet of soft foods, leaving erosive surfaces on the mucosa of cheeks, tongue, uvula and lips. Other possible manifestations of this disease are tongue denudation, vestibule obliteration, ankyloglossia and microstomia (16). In this case report, the patient presented most of these oral manifestations; only ankyloglossia was not evident.

The effect of EB on tooth formation and structure is unclear, and its clinical expression is highly variable (1). Liversigde et al. (17) suggested that permanent tooth maturation proceeds normally in children with DEB. Effects on dental enamel range from mild pit defects to severe hypoplasia, thin enamel or loss of enamel (18-20). Dentin formation in all types of EB appears to be normal, although taurodontism has been documented (19). Agenesis of the mandibular right lateral incisor was detected in the patient described in this paper. Lindemeyer et al. (6) reported on a patient with congenitally missing maxillary right lateral incisor.

The diet of patients with EB usually contains soft-consistency foods, as the solid foods might cause blister formation (17). In addition, a sucrose-rich diet is considered necessary to provide sufficient caloric intake to maintain the patient's growth (7). The abnormalities of the hands raise the difficulty to mechanical removal of dental plaque because of the decreased capacity to hold the toothbrush. Therefore, the soft consistency-highsucrose intake diet, the difficulty to hold the toothbrush due to the joined fingers and the fragility of oral tissues upon minor trauma contribute to a poor oral hygiene. As a result, the major dental complication of EB in general is the increased risk of caries $(20,21)$.

Wright et al. (21) have shown that the prevalence of caries was significantly higher in EB individuals than among healthy people. It has been hypothesized that excessive caries is a result of the presence and severity of the soft tissue involvement, which leads to alteration in diet, increased oral clearance time, creation of an abnormal tooth/soft tissue relationship and preventions of normal oral hygiene measures.

Dental treatment of these individuals is further complicated by their severe oral and perioral scarring, microstomia, ankyloglossia, loss of palatal rugae and lingual papillae, obliteration of the oral vestibule and limited mouth opening $(4,9)$. Thus, the treatment of the EB patient must be modified in order to decrease the effects of local trauma to the tissues. Oral ulceration due to trauma during dental manipulation is unavoidable, but it could be limited by the mucosa lubrication before any manipulation with hydrocortisone cream, triamcinalone or petroleum jelly $(2,9,16)$. In addition, the use of small-sized instruments, short-shaft dental burs, and handpieces with a small-sized head are indicated (9). Dentures and restorations should be carefully adapted and highly polished; secondary infections should be prevented with the use of oral antiseptics or using topical antibiotics on existing bullous lesions (22).

During the dental treatment in outpatient settings, the administration of local anesthesia to patients with EB may also cause blister formation and should therefore be avoided whenever possible (23). Nevertheless, when 
necessary, local anesthetic should be injected slowly and deeply into the tissues to prevent mechanical tissue separation and blistering (2).

Regarding dental treatment under general anesthesia, some authors (24) affirm that it can be complicated since the intubation predisposes the patient to high risk of pharyngeal and tracheal lesions. However, some authors state that the rate of new bulla formation associated with this procedure appears to be very rare when intubation is done gently with a smaller lubricated laryngoscope $(2,25)$. The benefits of outpatient treatment include the possibility of submitting the patient to less invasive dental procedures, lower cost and absence of hospitalization, thus eliminating the risks inherent to general anesthesia procedures and hospital infection.

Due to the difficulties related to the restorative dental treatment of these patients, the emphasis on the oral health management of these special needs children must be on prevention beginning at an early age. Instructions on toothbrushing and dietary habits must be strongly emphasized. Thus, small and soft-bristletoothbrushes or water-jet systems to mechanical removal of dental plaque were successfully indicated for oral hygiene of our patient in order to prevent oral mucosa trauma and blister formation.

The settlement of a realistic, comprehensive treatment planning relies on assessing the child's caries risk and activity, identifying the factors and conditions that most influence this status, and, above all, motivating the family to realize that positive attitudes towards oral health may dramatically reduce the likelihood and/or severity of caries disease. For ultimate benefit, information transmitted to parents or caregivers should take into account their background knowledge on dental care, socioeconomic status and educational level, and the directions must always be simple and easy to follow.

In many ways, parenting a child that suffers from any debilitating disorder is certainly a challenging, lifelong experience. The physical disabilities, limitations and medical problems of special children are sometimes so demanding that oral health care is not considered a priority. However, parents must be aware that negligent oral hygiene habits lead to dental problems that will inherently bring additional (and avoidable) pain, discomfort and complications for their children. Parental commitment to the dental treatment is paramount. When the dentist and the family completely understand the relevance of a partnership approach, noticeable and lasting outcomes in oral health care of these special patients should be expected.

It is noteworthy that some dentists do not feel comfortable or prepared for treating special needs individuals due to their lack of knowledge on the diseasespecific manifestations and implications. We hope that the issues discussed in this paper can be helpful to elucidate the most relevant clinical aspects and typical oral findings of patients with EB and provide researchbased information that can make oral health professionals more familiar with this condition and more qualified to offer a dental treatment of excellence.

EB is considered a serious skin and mucous membranes disorder. The abnormalities of the hands and the efforts to avoid mucosal trauma increase the difficulty to mechanical removal of dental plaque. Although carcinomas occur with far greater frequency on the skin in individuals with EB, they can occur intraorally. Therefore, the emphasis on the oral health management of these special needs children must be on prevention. An effective oral care and a preventive program should be earlier introduced in order to maintain their oral health. Extreme care during the dental treatment should be adopted to minimize the blisters and erosions lesions in the oral cavity. Understanding EB and its oral manifestations should help dentists outlining the best possible dental treatment with minor injuries to these patients.

\section{RESUMO}

Epidermólise bolhosa compreende um grupo heterogêneo de desordens genéticas raras caracterizadas pela fragilidade da pele e do tecido mucoso, nos quais surgem lesões bolhosas em resposta à injúrias traumáticas, ao calor ou até mesmo sem causa aparente. $\mathrm{Na}$ forma recessiva da doença, repetidos episódios de bolhas e formação de tecido cicatricial nos tecidos orais acabam por tornar a mucosa atrófica causando microstomia, anquiloglossia, desnudamento da língua e predisposição a desenvolvimento de carcinomas. Os simples cuidados rotineiros com a saúde bucal podem levar a formação das bolhas na mucosa bucal e nos lábios. A falta de higiene adequada associada a um consumo elevado de carboidratos e alimentos mais pastosos aumentam o risco de cárie nestes pacientes. Este relato documenta o caso de uma criança com diagnóstico de epidermólise bolhosa distrófica recessiva, descrevendo as dificuldades e as fases do tratamento odontológico realizado, enfatiza as medidas adotadas pelos profissionais de saúde para propiciar um tratamento seguro e efetivo, bem como a importância de se instituir um programa de prevenção bucal o mais precoce possível.

\section{REFERENCES}

1. Fine JD, Eady RA, Bauer EA, Bauer JW, Bruckner-Tuderman L, 
Heagerty A, et al.. The classification of inherited epidermolysis bullosa (EB): Report of the Third International Consensus Meeting on Diagnosis and Classification of EB. J Am Acad Dermatol 2008;58:931-950.

2. Stavropoulos F, Abramowicz S. Management of the oral surgery patient diagnosed with epidermolysis bullosa: report of 3 cases and review of the literature. J Oral Maxillofac Surg 2008;66:554-559.

3. Pacheco W, Marques de Sousa Araugio R. Orthodontic treatment of a patient with recessive dystrophic epidermolysis bullosa: a case report. Spec Care Dentist 2008;28:136-139.

4. Prabhu VR, Rekka P; Ramesh, Swathi S. Dental and anesthetic management of a child with epidermolysis bullosa. J Indian Soc Pedod Prev Dent 2011;29:155-160.

5. Silva IG, Alves JMA, Mattos LMBB, Francisquini RF. Epidermolysis bullosa. HU Rev 2000;26:221-227.

6. Lindemeyer R, Wadenya R, Maxwell L. Dental and anaesthetic management of children with dystrophic epidermolysis bullosa. Int J Paediatr Dent 2009;19:127-134.

7. Silva LC, Cruz RA, Abou-Id LR, Brini LN, Moreira LS. Clinical evaluation of patients with epidermolysis bullosa: review of the literature and case reports. Spec Care Dentist 2004;24:22-27.

8. Mitsuhashi Y, Hashimoto I. Genetic abnormalities and clinical classification of epidermolysis bullosa. Arch Dermatol Res 2003;295:S29-S33.

9. de Freitas AC, Ribeiro ZMM, de Oliveira MCT, Assed S. Clinical management of a case of epidermolysis bullosa. Rev Fac Odontol Ribeirao Preto 1986;23:71-78.

10. Wright JT. Oral Manifestations in the epidermolysis bullosa spectrum. Dermatol Clin 2010;28:159-164.

11. Azarian M, Dreux S, Vuillard E, Meneguzzi G, Haber S, Guimiot F, et al.. Prenatal diagnosis of inherited epidermolysis bullosa in a patient with no family history: a case report and literature review. Prenat Diagn 2006;26:57-59.

12. Yamada M, Hatta N, Sogo K, Komura K, Hamaguchi Y, Takehara $\mathrm{K}$. Management of squamous cell carcinoma in a patient with recessive-type epidermolysis bullosa dystrophica. Dermatol Surg 2004;30:1424-1429.

13. Fine JD, Johnson LB, Weiner M, Li KP, Suchindran C. Epidermolysis bullosa and the risk of life-threatening cancers: the National EB Registry experience, 1986-2006. J Am Acad
Dermatol 2009;60:203-211.

14. Schwartz RA, Birnkrant AP, Rubenstein DJ, Kim U, Burgess GH, Stoll HL Jr., et al.. Squamous cell carcinoma in dominant type epidermolysis bullosa dystrophica. Cancer 1981;47:615-620.

15. Olsen CB, Bourke LF. Recessive dystrophic epidermolysis bullosa. Two case reports with 20-year follow-up. Aust Dent J 1997;42:1-7.

16. Serrano-Martínez MC, Bagán JV, Silvestre FJ, Viguer MT. Oral lesions in recessive dystrophic epidermolysis bullosa. Oral Dis 2003;9:264-268.

17. Liversidge HM, Kosmidou A, Hector MP, Roberts GJ. Epidermolysis bullosa and dental developmental age. Int J Paediatr Dent 2005;15:335-341.

18. Wright JT, Johnson LB, Fine JD. Development defects of enamel in humans with hereditary epidermolysis bullosa. Arch Oral Biol 1993;38:945-955.

19. Wright JT, Gantt DG. Epidermolysis bullosa associated with enamel hypoplasia and taurodontism. J Oral Pathology 1983;12:73-83.

20. Wright JT. Oral manifestations in the epidermolysis bullosa spectrum. Dermatol Clin 2010;28:159-164.

21. Wright JT, Fine JD, Johnson L. Dental caries risk in hereditary epidermolysis bullosa. Pediatr Dent 1994;16:427-432.

22. Siqueira MA, de Souza Silva J, Silva FW, Díaz-Serrano KV, Freitas AC, Queiroz AM. Dental treatment in a patient with epidermolysis bullosa. Spec Care Dent 2008;28:92-95.

23. Kostara A, Roberts GJ, Gelbier M. Dental maturity in children with dystrophic epidermolysis bullosa. Pediatr Dent 2000;22:385-388.

24. Herod J, Denyer J, Goldman A, Howard R. Epidermolysis bullosa in children: pathophysiology, anaesthesia and pain management. Paediatr Anaesth 2002;12:388-397.

25. Iohom G, Lyons B. Anaesthesia for children with epidermolysis bullosa: a review of 20 years' experience. Eur J Anaesthesiol 2001;18:745-754.

Received December 15, 2010 Accepted October 1, 2011 